\title{
Ethylene Production throughout Growth and Development of Plants
}

\author{
Raymond M. Wheeler, ${ }^{1}$ Barbara V. Peterson, and Gary W. Stutte \\ NASA Biological Research Office and Dynamac Corp. Kennedy Space Center, FL 32899
}

\begin{abstract}
Ethylene production by 10 or $20 \mathrm{~m}^{2}$ stands of wheat, soybean, lettuce, potato, and tomato was monitored throughout growth and development in an atmospherically closed plant chamber. Chamber ethylene levels varied among species and rose during periods of canopy expansion and rapid growth for all species. Following this, ethylene levels either declined during seed fill and maturation for wheat and soybean, or remained relatively constant for potato and tomato (during flowering and early fruit development). Lettuce plants were harvested during rapid growth and peak ethylene production. Chamber ethylene levels increased rapidly during tomato ripening, reaching concentrations about 10 times that measured during vegetative growth. The highest ethylene production rates during vegetative growth ranged from 1.6 to $2.5 \mathrm{nmol} \cdot \mathrm{m}^{-2} \cdot \mathrm{d}^{-1}$ during rapid growth of lettuce and wheat stands, or about 0.3 to $0.5 \mathrm{nmol} \cdot \mathrm{g}^{-1}$ fresh weight per hour. Estimates of stand ethylene production during tomato ripening showed that rates reached $43 \mathrm{nmol} \cdot \mathrm{m}^{-2} \cdot \mathrm{d}^{-1}$ in one study and $93 \mathrm{nmol} \cdot \mathrm{m}^{-2} \cdot \mathrm{d}^{-1}$ in a second study with higher lighting, or about $50 \times$ that of the rate during vegetative growth of tomato. In a related test with potato, the photoperiod was extended from 12 to 24 hours (continuous light) at 58 days after planting (to increase tuber yield), but this change in the environment caused a sharp increase in ethylene production from the basal rate of 0.4 to $6.2 \mathrm{nmol} \cdot \mathrm{m}^{-2} \cdot \mathrm{d}^{-1}$. Following this, the photoperiod was changed back to $12 \mathrm{~h}$ at 61 days and ethylene levels decreased. The results suggest three separate categories of ethylene production were observed with whole stands of plants: 1) production during rapid vegetative growth, 2) production during climacteric fruit ripening, and 3) production from environmental stress.
\end{abstract}

\section{Background and Methods}

Ethylene is one of the most important compounds in horticulture and its effects on plants have studied for nearly 100 years (Abeles et al., 1992; Burg and Burg, 1965; Crocker et al; 1932; Denny, 1924). Ethylene is the lightest of the alkene series of hydrocarbons $\left(\mathrm{H}_{2} \mathrm{C}=\mathrm{CH}_{2}, \mathrm{MW}\right.$ 28 ) and occurs as a gas under Earth ambient conditions (e.g., $\approx 300 \mathrm{~K}$ and $\approx 100 \mathrm{kPa}$ pressure); hence, measuring ethylene for plant research typically uses direct gas analysis, e.g., gas chromatography (Abeles et al., 1992). These measurements are often carried out by placing plant tissues (e.g., leaves, fruit, etc.) in a sealed vessel or chamber and then analyzing the headspace of the vessel (Abeles et al., 1992). The tissues can be degassed using vacuum techniques (e.g., Beyer and Morgan, 1970) or allowed to incubate permitting ethylene to accumulate. These procedures are relatively convenient and can target different organs or tissues, but they are limited by the size and types of tissue that can be enclosed for sampling. In addition, this approach generally requires excision or manipulations resulting in wounding, which can generate ethylene, and often exposes the tissue to different $\mathrm{CO}_{2}$ and $\mathrm{O}_{2}$ concentrations, which also can affect ethylene production (Abeles et al., 1992; Bassi and Spencer, 1979). An alternative approach is to place whole plants or intact organs (e.g., fruit) in a controlled environment that is atmospherically sealed (Bassi and Spencer, 1979; De Greef and De Provitt, 1978). This allows observations of ethylene production with minimal perturbation and provides the integrated measure of whole plants or communities of plants. Unfortunately this latter technique requires controlled environment chambers that are sufficiently large to accommodate whole plants, and the atmosphere must either be closed (to allow ethylene accumulation) or ventilated such that the air stream passes through a sorbent material, which can later be degassed and sampled (Bassi and Spencer, 1979; Saito et al., 1996).

Measurements of ethylene production by plants are especially pertinent to spaceflight applications, where research on $\mu$-gravity effects and the use of plants for human life support are being studied (Krikorian and Levine, 1992; Wheeler et al., 2001). Because spacecraft must be protected from the vacuum and harsh environments of space, the atmosphere must be tightly sealed and controlled. Thus, any ethylene

Received for publication 2 June 2003. Accepted for publication 1 Feb. 2004 We wish to thank Cheryl Mackowiak, Lisa Ruffe, and Neil Yorio, horticultural assistance, Betsy Berdis and Steve Mosakowski for analytical assistance, and Russ Fortson, Joe Martinez, Jim Bledsoe, and Joe Benjamin for engineering support.

${ }^{1}$ Corresponding author: NASA Mail Code YA-E4-B, Kennedy Space Center, FL 32899; e-mail Raymond.M.Wheeler@nasa.gov. produced in these environments can accumulate and cause problems; moreover, these problems can be exacerbated if ethylene production is increased by the low-gravity environment of space (Crocker et al., 1932; Leather et al., 1972; Wheeler et al., 1986).

For the past 25 years or so, NASA and other space agencies have been conducting tests in controlled environments to assess the potential for using plants to provide human life support (Wheeler et al., 2001). As part of this effort, our group at Kennedy Space Center conducted tests with various crops in a large, atmospherically closed chamber that simulated the sealed conditions that might be encountered in space. The chamber provided a closed volume of $113 \mathrm{~m}^{3}$ with an available planting area of $20 \mathrm{~m}^{2}$, and was used to track whole-stand photosynthesis (e.g., Wheeler, 1992; Wheeler et al., 1993). As part of the testing, we were able to observe ethylene buildup throughout crop growth and development. For all of these studies, the crops were grown using recirculating nutrient film technique (without any solid rooting medium), lighting was provided by $96400-\mathrm{W}$ high-pressure sodium and/or 400-W metal halide lamps, and $\mathrm{CO}_{2}$ concentrations were enriched to 1000 or $1200 \mu \mathrm{mol} \cdot \mathrm{mol}^{-1}$ ( 0.10 to $0.12 \mathrm{kPa}$ ). Studies used 20- $\mathrm{m}^{2}$ stands (monocultures) of wheat (Triticum aestivum L. 'Yecora Rojo'), soybean (Glycine max [Merr.] L. 'McCall'), lettuce (Lactuca sativa L. 'Waldmann's Green'), and potato (Solanum tuberosum L. 'Norland') and 10- or 20- $\mathrm{m}^{2}$ stands of tomato (Lycopersicon esculentum [L.] Mill. 'Reimann Philipp') (Wheeler et al., 1996). Ethylene in the chamber atmosphere was monitored throughout growth using gas chromatography (GC) with photoionization detection (PID) (Photovac $10 S 70$ and Photovac 10S Plus). The GC/PID was set to automatically sample the air via $3.2 \mathrm{~mm}$ o.d. $\times 76 \mathrm{~mm}$ Teflon lines. Four different columns were used at various times during the different studies: 1) $183 \mathrm{~cm} \times 3.2 \mathrm{~mm} \mathrm{6.6 \%} \mathrm{CSP-20M} \mathrm{on} \mathrm{Carbopak} \mathrm{B} \mathrm{and} 183 \mathrm{~cm} \times 3.2$ mm Carbopak BHT 100 in tandem with 15-cm precolumn; 2) $244 \mathrm{~cm}$ $\times 3.2 \mathrm{~mm}$ XE-60 on Carbopak B with $15-\mathrm{cm}$ precolumn; 3) $900 \mathrm{~cm}$ $\times 0.53 \mathrm{~mm} \mathrm{KCL} /$ Alumina fused silica with precolumn; 4) $900 \mathrm{~cm} \times$ $0.53 \mathrm{~mm}$ CP-Sil $5 \mathrm{cB}$ with precolumn. The detector gain was set at 1,000 for greatest sensitivity and the isothermal oven was set at $30^{\circ} \mathrm{C}$. Ultra-pure air carrier gas was set at $15 \mathrm{~mL} \cdot \mathrm{min}^{-1}$. Detectable limits of $2 \mathrm{ppb}\left(\mathrm{nmol} \cdot \mathrm{mol}^{-1}\right)$ were calculated. Replicate injections of ethylene standards showed variability of $<1 \%$ and a standard deviation of 0.27 $\mathrm{ppb}$. Changing the column, injecting the standard and sample, and then comparing retention times verified the presence of ethylene. Chamber leakage was determined to be about $10 \%$ of the volume per day using $\mathrm{CO}_{2}$ concentration decay tests without any plants in the chamber (Wheeler, 1992). Large amounts of transpired water were condensed and removed from the chamber during plant growth (up to about 100 


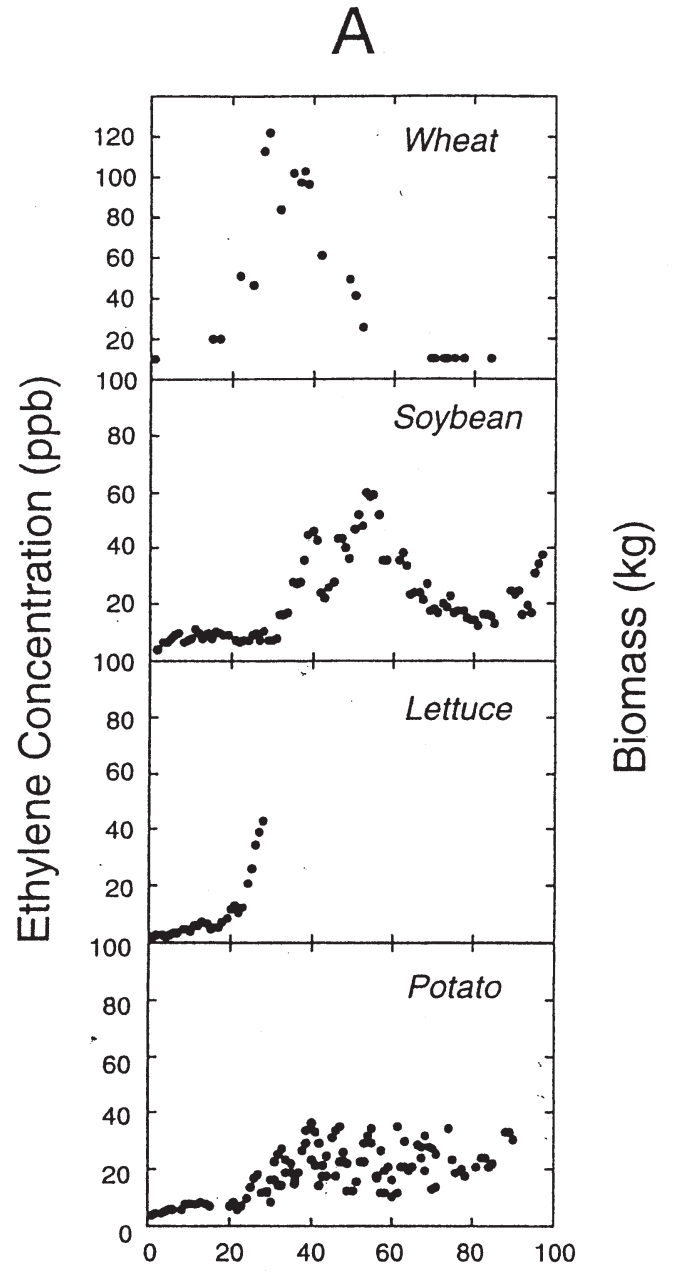

Days After Planting

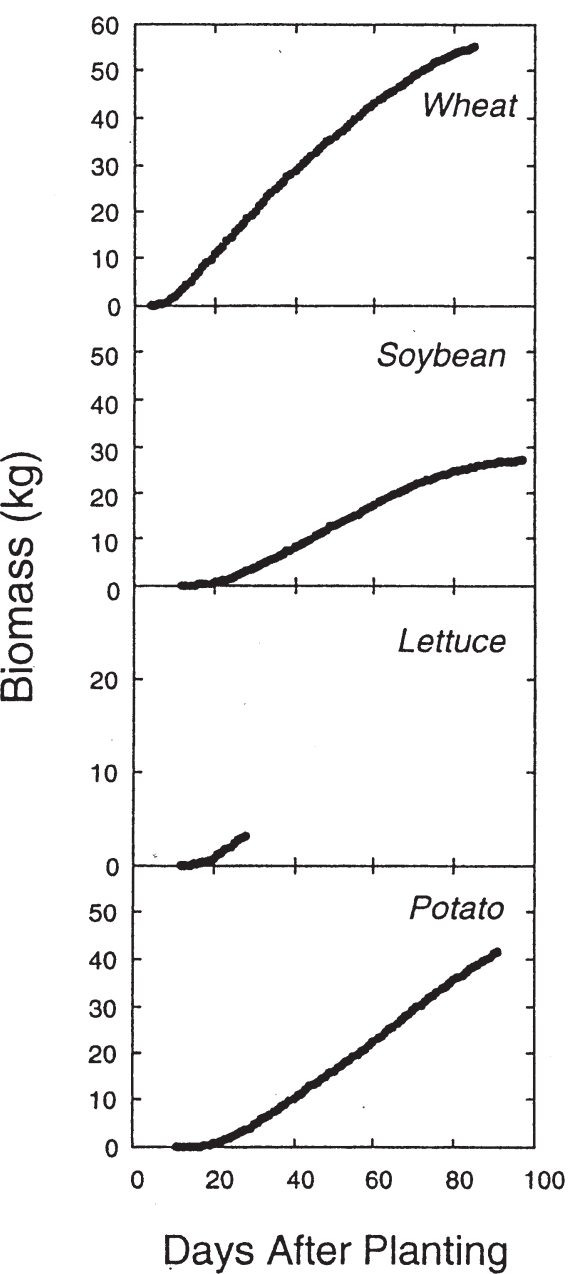

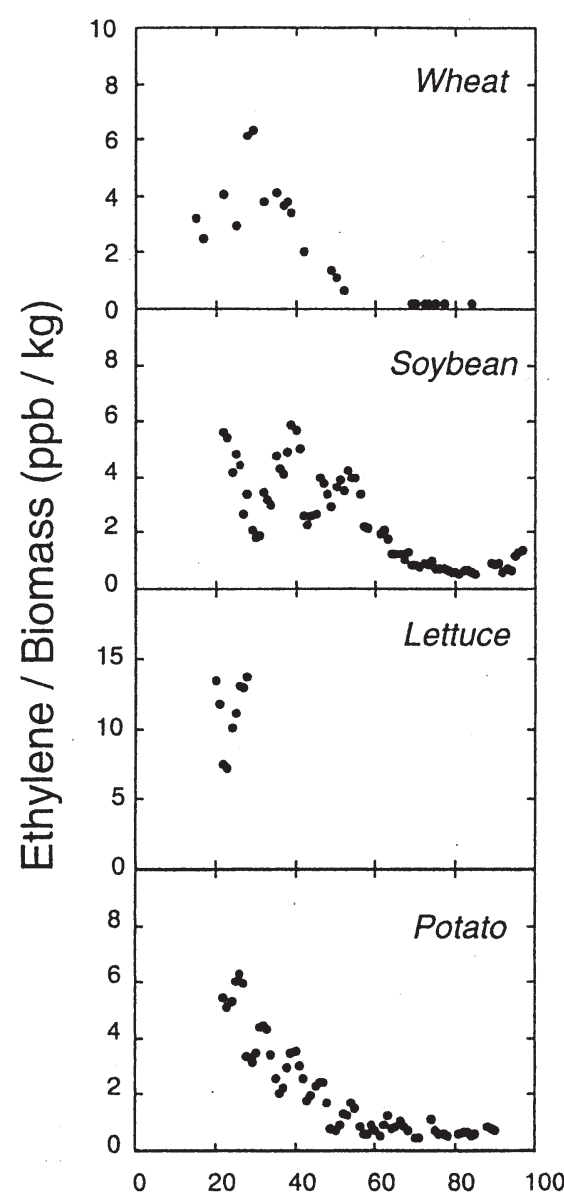

Days After Planting

Fig. 1. Ethylene concentrations in NASA's Biomass Production Chamber over time for $20 \mathrm{~m}^{2}$ crops of wheat, soybean, potato, and lettuce grown through typical production cycles $(\mathbf{A})$. Accumulation of biomass for each of the crops was estimated by $\mathrm{CO}_{2}$ uptake rates $(\mathbf{B})$. Dividing the chamber concentrations $(\mathbf{A})$ by cumulative biomass $(\mathbf{B})$ shows relative concentrations normalized for the amount of plant materials $(\mathbf{C})$.

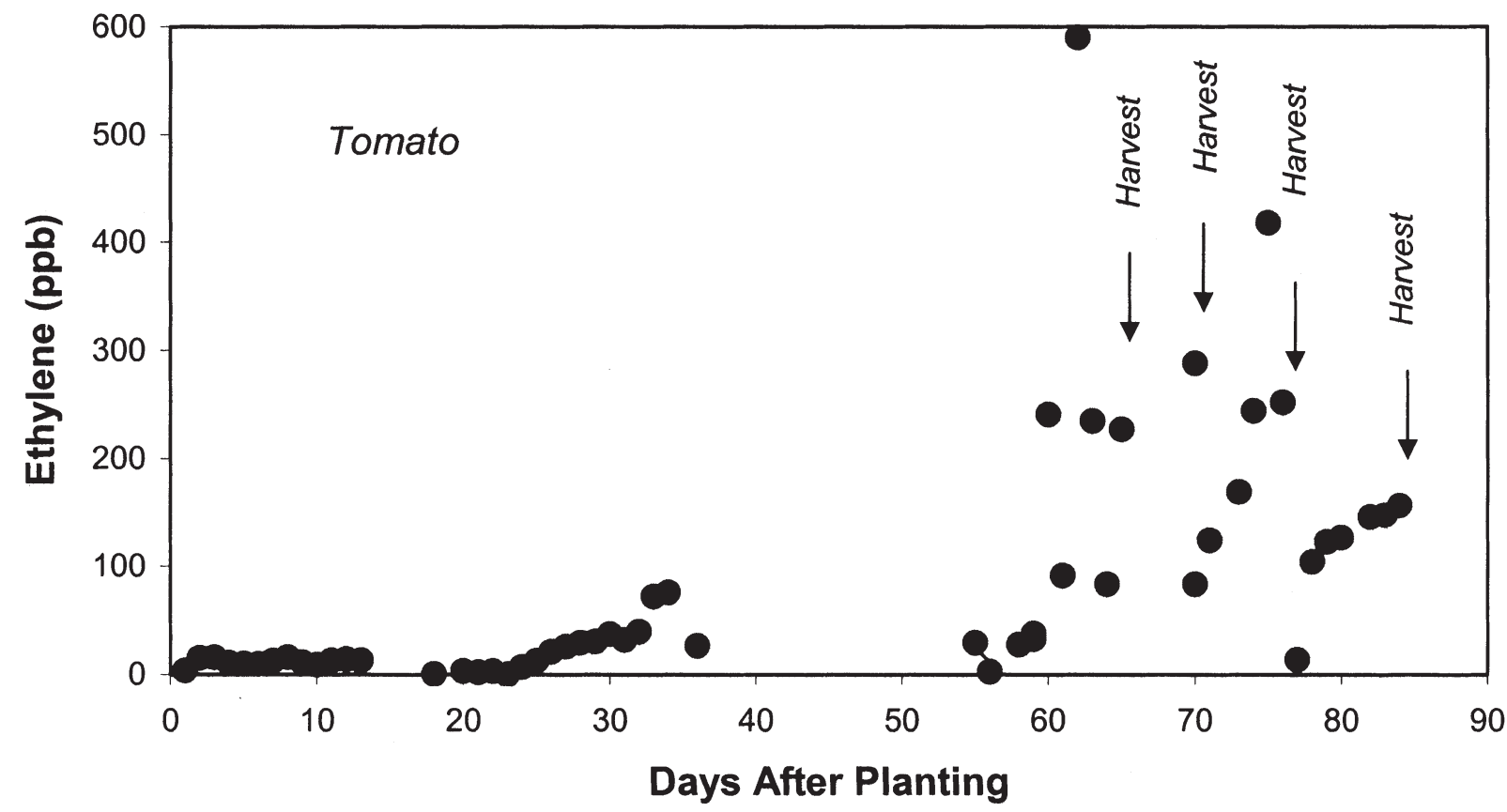

Fig. 2. Ethylene concentrations during the growth and development of tomato plants in NASA's Biomass Production Chamber. Ethylene concentrations rose rapidly during fruit ripening (beginning about day 60), showing a climacteric type response. Arrows indicate dates when ripe fruit were harvested (removed) from the chamber. 


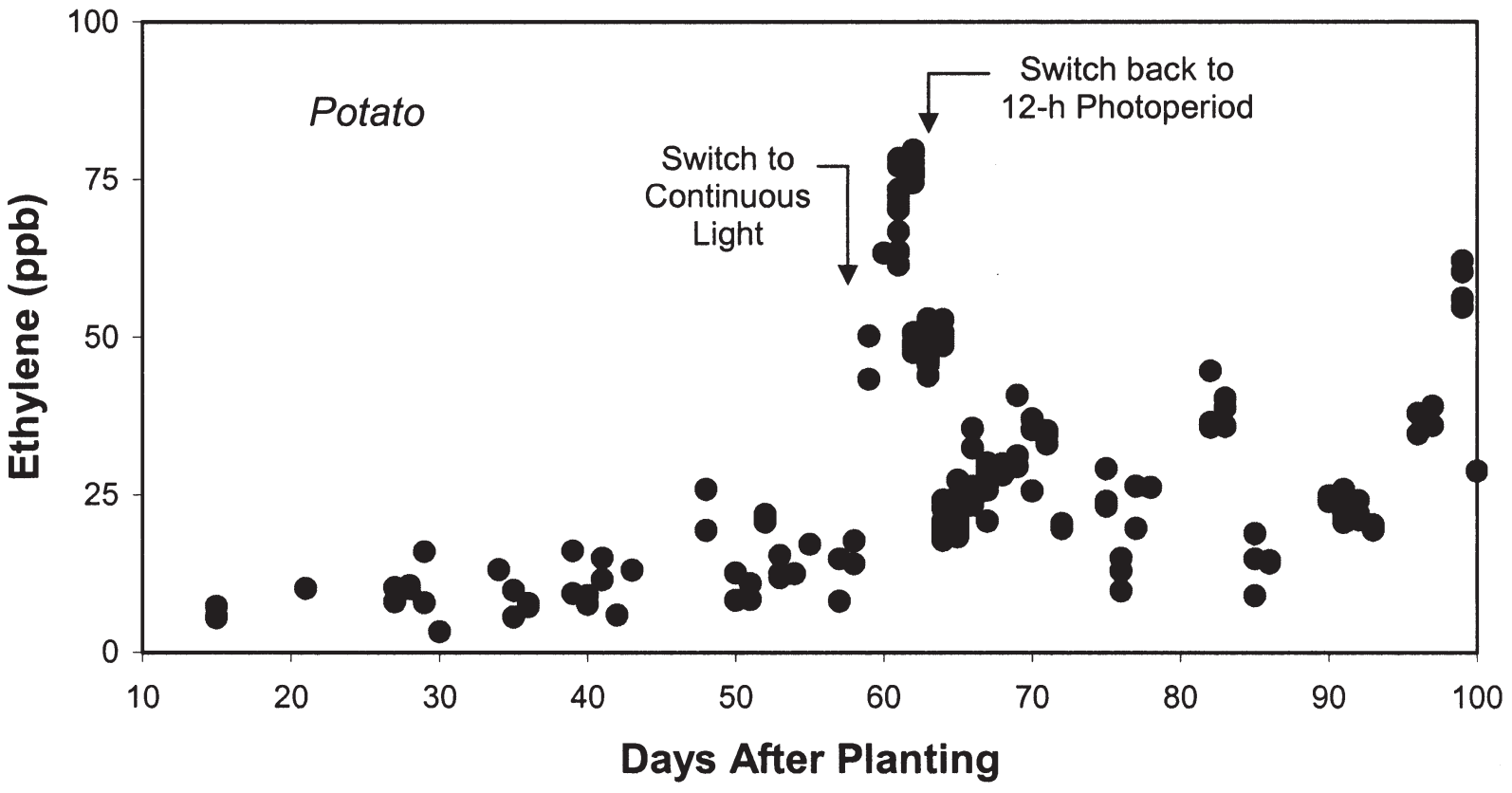

Fig. 3. Ethylene concentrations during growth and development of a potato stand. The photoperiod was increased form $12 \mathrm{~h}$ light/ $12 \mathrm{~h}$ dark to $24 \mathrm{~h}$ (continuous) light on day 58. This resulted in a rapid increase in ethylene concentration and an apparent stress to the crop (photosynthetic rates dropped following this change). The photoperiod was changed back to $12 \mathrm{~h}$ light/ $12 \mathrm{~h}$ dark on day 61, after which ethylene concentrations decreased.

$\mathrm{L} \cdot \mathrm{d}^{-1}$ from full $20-\mathrm{m}^{2}$ stands), but ethylene is relatively insoluble in water $(\approx 1 \mathrm{~mL}$ of ethylene dissolved into $9 \mathrm{~mL}$ of water under pure ethylene; Abeles et al., 1992) and hence any ethylene leaving the system through condensate was ignored. Rates of ethylene production were estimated using changes in concentration over fixed time intervals (without any leakage corrections), or by comparing peak concentrations and determining the amount of production needed to offset the leakage at these points. Periodic entries (door openings) to the chamber were required for routine horticultural activities, resulting in temporary increases in leakage, and no data were used from these time periods for calculating ethylene production rates.

\section{Results and Discussion}

Atmospheric measurements made before planting showed low $(<10 \mathrm{ppb})$ or undetectable levels of ethylene, indicating that construction materials and internal components of the chamber were not a significant source of ethylene. Results showed that ethylene production varied among species, reaching peak levels of $120 \mathrm{ppb}$ with wheat, $60 \mathrm{ppb}$ with soybean, and 40 to $50 \mathrm{ppb}$ for lettuce and potato (Fig. 1A). Wheat studies showed a distinctive rise early in growth followed by a decline during head maturation and senescence. Peak ethylene production by wheat occurred during rapid vegetative growth, about $30 \mathrm{~d}$, close to when the highest rates of photosynthesis, respiration, and nutrient uptake of the stand were occurring (Wheeler et al., 1993). For soybean, ethylene concentration peaked near $50 \mathrm{~d}$, declined during pod fill, and showed a slight increase about harvest(Fig. 1A). Lettuce studies showed a rapid rise in ethylene beginning near 20 to $24 \mathrm{~d}$ and continued to harvest at $28 \mathrm{~d}$.

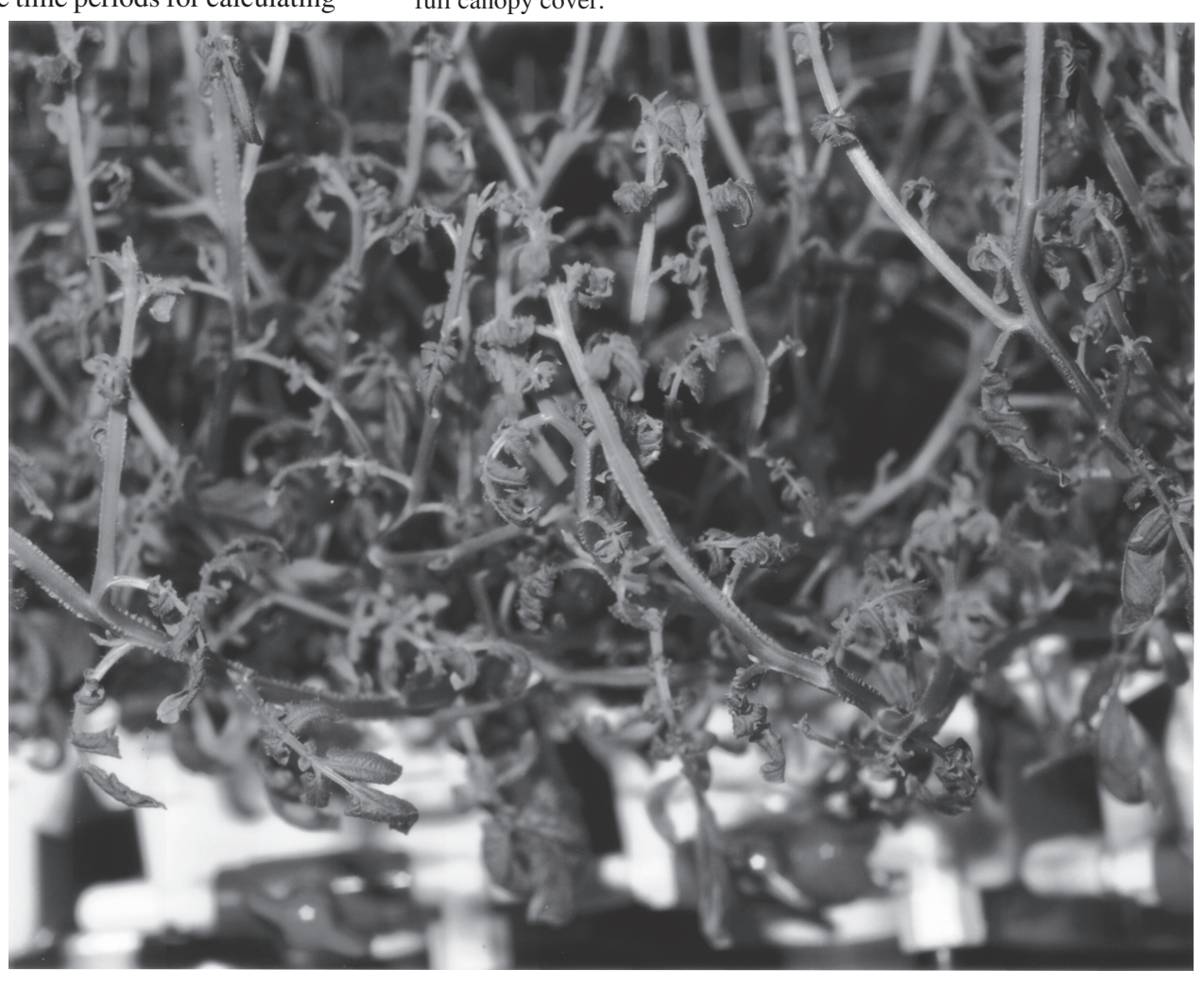

Ethylene levels during potato studies typically showed a gradual rise during early growth until about day 40 , followed by relatively constant levels throughout maturation. Tubers typically appeared near $30 \mathrm{~d}$ after planting and continued to enlarge thereafter.

Except for lettuce, ethylene concentrations in the chamber did not continue to increase over time, suggesting that chamber leakage outstripped plant production during later stages of growth. It is possible microbes in the plant rhizosphere and nutrient solution could have been a source of ethylene (Arshad and Frakenberger, 2002), or that microbes could have metabolized some ethylene. But analysis of the solution microflora showed little change in species composition and total counts following planting (Strayer, 1991), suggesting that

Fig. 4. Epinastic leaves on potato plants grown in an atmospherically closed chamber where ethylene concentrations ranged from 40 to $50 \mathrm{ppb}$. Epinasty was only noted on young expanding leaves of axillary branches following full canopy cover. 


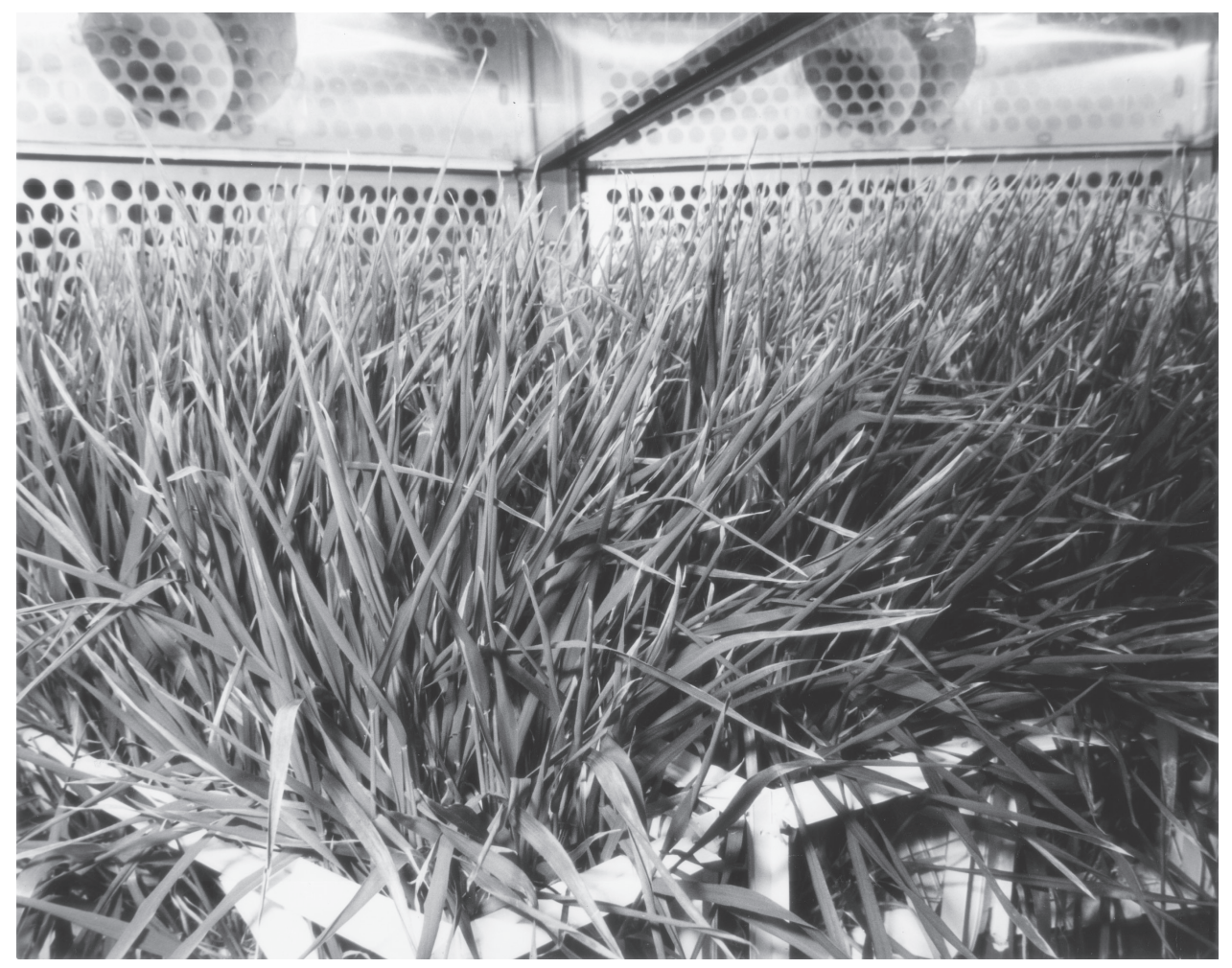

production rate of $93 \mathrm{nmol} \cdot \mathrm{m}^{-2} \cdot \mathrm{d}^{-1}$. As with estimates of ethylene production rates during vegetative growth, these rates are most likely conservative due to chamber leakage.

Tomato is a climacteric type species and ripening fruit tissues are known to go through a different ethylene metabolic sequence than vegetative tissues (Alexander and Grierson, 2002), and it is likely that autocatalysis occurred during this phase of growth (i.e., ethylene promoted the production of more ethylene). 'Reimann Philipp' is determinate and largely parthenocarpic for fruit set and thus it is not clear whether the high ethylene concentrations would have adverse effects on less determinate cultivars that continue to flower and produce fruit through pollination/fertilization(Klassen and Bugbee, 2003).

In addition to the large climacteric burst of ethylene in the tomato studies, a large increase in ethylene also occurred in a potato study in which the photoperiod was extended from $12 \mathrm{~h}$ light $/ 12 \mathrm{~h}$ dark to $24 \mathrm{~h}$ (constant) light at $58 \mathrm{~d}$ after planting. Within 24 to $48 \mathrm{~h}$ following the change to continuous light,

Fig. 5. Longitudinally (epinastically) rolled flag leaves of wheat plants grown in an atmospherically closed chamber where ethylene concentrations reached $120 \mathrm{ppb}$.

microbial effects, if any, were constant over time. It is also possible that the plants metabolized (oxidized) some ethylene, but the rates would likely be low and not affect overall concentrations (Raskin and Beyer, 1989). Collectively, these observations indicate that the plants were the primary source of the ethylene, and that chamber leakage was the primary factor in decreasing any elevated ethylene concentrations.

If ethylene concentrations were normalized for standing biomass (estimated from assimilated $\mathrm{CO}_{2}$; Fig. 1B), lettuce showed the highest ethylene concentration per unit biomass (Fig. 1C). Other species showed a trend of high production when plants were young followed by a gradual decrease with age (Fig. 1C). These observations from whole stands are consistent with data from excised tissue of bean plants (Phaseolus vulgaris) (Roberts and Osborne, 1981) suggesting that ethylene production by plant stands is a normal occurrence during healthy vegetative growth. Peak rates of production during rapid growth of wheat and lettuce stands ranged from 8 to $10 \mathrm{ppb} / \mathrm{d}$, or 1.6 to 2.5 $\mathrm{nmol} \cdot \mathrm{m}^{-2}$ stand area per day, which equates to about $0.6 \mathrm{nmol} \cdot \mathrm{g}^{-1}$ dry weight per hour $\left(0.04 \mathrm{nmol} \cdot \mathrm{g}^{-1}\right.$ fresh weight per hour $)$ for lettuce and $0.3 \mathrm{nmol} \cdot \mathrm{g}^{-1}$ dry weight per hour $\left(0.03 \mathrm{nmol} \cdot \mathrm{g}^{-1}\right.$ fresh weight per hour $)$ for wheat. These estimates are likely conservative because of slow leakage from the chamber. Because plants were still alive at harvest (wheat and soybean shoots were partially dry), ethylene production during final stages of senescence was not monitored and could have increased somewhat, as suggested in the soybean study (Fig. 1A) (Aharoni and Lieberman, 1979).

Unlike the other species, tomatoes showed a very different ethylene production pattern: Chamber ethylene concentrations were generally low during early growth, but as fruit began to ripen (about day 55) ethylene rose rapidly reaching the highest levels $(\approx 600 \mathrm{ppb})$ of any of the studies (Fig. 2). Ripe fruit were harvested several times during these studies, which reduced ethylene concentrations (much of this was also due to the opening of the door). But in each case concentrations increased again as additional fruit ripened (Fig. 2). Although the concentration data are noisy due to the periodic entrances to harvest fruit, an increase of $560 \mathrm{ppb}$ between days 59 to 61 suggest that stand ethylene production was about $43 \mathrm{nmol} \cdot \mathrm{m}^{-2} \cdot \mathrm{d}^{-1}$. In another study with tomato plants grown at higher PAR levels (not shown), ethylene concentrations rose nearly $400 \mathrm{ppb}$ in $1 \mathrm{~d}$ during a period of rapid fruit ripening for a stand potato stand ethylene levels rose to nearly $80 \mathrm{ppb}$ (Fig. 3). During this same period, instantaneous photosynthetic rates decreased. This combination of symptoms suggested the continuous light stressed the plants and consequently the photoperiod was changed back to a $12 \mathrm{~h}$ light/ $12 \mathrm{~h}$ dark cycle. Following this, ethylene concentrations dropped although photosynthetic rates never fully recovered. Based on the time course of concentration rise, ethylene production rates in response to the change to continuous light were about $6.2 \mathrm{nmol} \cdot \mathrm{m}^{-2} \cdot \mathrm{d}^{-1}$, nearly 15 times greater than the basal rate of $0.4 \mathrm{nmol} \cdot \mathrm{m}^{-2} \cdot \mathrm{d}^{-1}$ about change to continuous light. Although the continuous light can promote faster tuber development, it can also be stressful to potato plants in certain circumstances (Wheeler and Tibbitts, 1986), and the rapid rise in ethylene in response to this change suggests that the continuous light induced photooxidative stress.

With the exception of some later studies with tomato and wheat where ethylene concentrations were not monitored closely, no attempts were made to scrub or reduce ethylene levels in most of these tests. Expanding potato leaves on axillary branches often showed epinasty (Fig. 4) and flag leaves of wheat showed longitudinal, epinastic rolling (similar to a soda straw) soon after peak ethylene levels were measured (Fig. 5). Epinasty is a classic symptom of ethylene exposure (Abeles et al., 1992; Crocker et al., 1932) and in the case of potato leaves, this occurred with the chronic exposures of only 40 to $50 \mathrm{ppb}$ ethylene. This finding is consistent with recent results from Klassen and Bubgee $(2002,2003)$, and suggests that exposures to ethylene even at seemingly low levels can cause responses in some plants.

There are few reports of ethylene measurements for intact plant canopies in the literature. Tani et al. (1993) reported ethylene accumulating to $0.15 \mathrm{ppm}$ after a closure test with lettuce plants and Shiitake mushrooms, and Saito et al. (1996) grew rice plants in closed chambers and reported production rates up to about $2 \mathrm{nmol} / \mathrm{plant}$ per hour during the heading stage of growth. In each case these were relatively small chambers $\left(<1 \mathrm{~m}^{2}\right.$ area $)$ compared to the 10 and $20 \mathrm{~m}^{2}$ planting areas used in our studies (see also, Wheeler et al., 1996). In addition to our studies, other NASA-sponsored testing reported ethylene buildup in an $11-\mathrm{m}^{2}$ closed chamber containing wheat plants Edeen et al. (1996).

Could ethylene accumulation be a problem for plant growth systems envisioned for space? The International Space Station is required to keep ethylene below $50 \mathrm{ppb}$ through the use of its trace contaminant control system, and the plant chambers used in space vary in their degree of closure, with some open to cabin air for cooling and $\mathrm{CO}_{2}$ supply, while others are relatively closed to provide better environmental control. 
Chronic exposures to 50 to $100 \mathrm{ppb}$ reduced growth in lettuce and Easter lily (Blankenship et al., 1993; Mortensen, 1989), levels of <50 ppb reduced seed set in rice and wheat (Klassen and Bugbee, 2002), and our studies showed that leaf epinasty occurred in potato at levels of 40 to $50 \mathrm{ppm}$ (Figs. 4 and 5). Although leaf epinasty may not be directly harmful, it could result in reduced light interception thereby slowing growth (Woodrow and Grodzinski, 1989). At the production rates noted for wheat during rapid growth, maximum levels in a system with leakage of only $1 \% \mathrm{vol} / \mathrm{d}$ would exceed $1.0 \mathrm{ppm}$, which could result in little or no seed set (Klassen and Bugbee, 2002). Related studies with wheat at NASA's Johnson Space Center using a more tightly sealed chamber with wheat plants showed that ethylene levels exceeded 800 $\mathrm{ppb}$, resulting in poor seed production (Edeen et al., 1996). In addition, experiments on growing wheat to maturity in space initially failed to produce viable seed, and this was later attributed to the high $(\approx 1$ to 2 ppm) ethylene levels in Mir Space Station atmosphere (Bingham et al., 2000; Salisbury, 1997). Subsequent tests in which cabin ethylene levels were reduced resulted in successful seed production by the wheat plants (Bingham et al., 2000; Salisbury, 1997)

Preliminary tests in our large chamber showed that potassium permanganate filters were effective for controlling ethylene (Martin and Sinnaeve, 1987). Tests with catalytic burners, UV degradation, selective membranes, different sorbents, or even ethylene metabolizing microbes also have been considered for ethylene control (Abeles et al., 1992; Eastwell et al., 1978). Questions then arise as to whether some ethylene in the atmosphere might be beneficial during certain stages of development and whether ethylene should be managed to optimize growth, much as is done with $\mathrm{CO}_{2}$ and humidity. For example, tomato fruit ripening was delayed in one of our studies where potassium permanganate filters were added to the air ducts, but then accelerated after the filters were exhausted. Answers to these questions may be critical to the use of plants and horticulture for bioregenerative life support systems in future space travel.

\section{Literature Cited}

Abeles, F.B., P.W. Morgan, and M.E. Saltveit. 1992. Ethylene in plant biology. vol. 2. Academic Press, Inc. San Diego, Calif..

Aharoni, M. and M. Lieberman. 1979. Patterns of ethylene production in senescing leaves. Plant Physiol. 64:796-800.

Alexander, L. and D. Grierson. 2002. Ethylene biosynthesis and action in tomato: A model for climacteric fruit ripening. J. Expt. Bot. 53:2039-2055.

Arshad, M. and W.T. Frakenberger. 2002. Factors affecting microbial production of ethylene, p.97-137. In: M. Arshad and W.T. Frakenberger (eds.). Ethylene: Agricultural sources and applications. Kluwer Academic/Plenum Publ.

Baldwin, E. Ethylene and postharvest commodities. HortScience 39(7):15381540.

Bassi, P.K. and M.S. Spencer. 1979. A cuvette design for measurement of ethylene production and carbon dioxide exchange by intact shoots under controlled environments conditions. Plant Physiol.64:488-490.

Beyer, E.M. and P.W. Morgan. 1970. A method for determining the concentration of ethylene in the gas of vegetative plant tissue. Plant Physiol. 46:352-354.

Bingham, GE, Levinskikh, MA, Sytchev VN, and IG Podolsky. 2000. Effects of gravity on plant growth. J. Gravitational Physiol. 7:5-8.

Blankenship, S.M., D.A. Bailey, and J.E. Miller. 1993. Effects of continuous, low levels of ethylene on growth and flowering of Easter lily. Scientia Hort. 53:311-317.

Burg, S.P. and E.A. Burg. 1965. Ethylene action and the ripening of fruit. Science 148:1190-1195.
Crocker, W., P.W. Zimmerman, and A.E. Hitchcock. 1932. Ethylene-induced epinasty of leaves and the relation of gravity to it. Contrib. Boyne Thompson Inst. Plant Res. 4:177-218.

De Greef, J.A. and M. De Profitt. 1978. Kinetic measurements of small ethylene changes in an open system designed for plant physiological studies. Physiol. Plant. 42:79-84.

Denny, F.E. 1924. Hastening the coloration of lemons. J. Agr. Res. 27:757769

Eastwell, K.C., P.K. Bassi, and M.E. Spencer. 1978. Comparison and evaluation of methods for the removal of ethylene and other hydrocarbons from air for biological studies. Plant Physiol. 62:723-726.

Edeen, M.A., J.S. Dominick, D.J. Barta, and N.J.C Packham. 1996. Control of air revitalization using plants: Results of the early human testing initiative Phase I Test. SAE Tech. Paper Ser. 961522.

Klassen, S.P. and B. Bugbee. 2002. Sensitivity of wheat and rice to low levels of atmospheric ethylene. Crop Sci. 42:746-753.

Klassen, S.P. and B. Bugbee. 2003. Ethylene synthesis and sensitivity in crop plants. HortScience 39(7):1546-1552.

Krikorian, A.D. and H.G. Levine. 1991. Development and growth in space, p. 491-555. In: R.G.S. Bidwell (ed.). Plant physiology: A treatise. Academic Press, Orland, Fla.

Leather, G.R., L.E. Forrence, and F.B. Abeles. 1972. Increased ethylene production during clinostat experiments may cause leaf epinasty Plant Physiol. 49:183-186.

Martin, J.K. and J. Sinnaeve. 1987. Removal of ethylene from the atmosphere of controlled environment chambers operated with full air recirculation. Soil Biol. Biochem. 19:651.

Mortensen, L.M. 1989. Effect of ethylene on growth of greenhouse lettuce at different light and temperature levels. Scientia Hort. 39: 97-103.

Raskin, I. and E.M. Beyer. 1988. Role of ethylene metabolism in Amaranthus retroflexus. Plant Physiol. 90:1-5.

Roberts, J.A. and D.J. Osborne. 1981. Auxin and the control ethylene production during the development and senescence of leaves and fruit. J. Expt. Bot. 32:875-887.

Saito, T., A. Tani, M. Kiyota, M. Ohe, and H. Sato. 1996. Rates of ethylene release, photosynthesis and transpiration of rice measured in closed-type chamber. Acta Hort. 440:55-59.

Salisbury, F.B. 1997. Growing Super-Dwarf wheat in space station MIR. Life Support Biosphere Sci. 4:155-166.

Strayer, R.F. 1991. Microbiological characterization of the Biomass Production Chamber hydroponic growth of crops at the CELSS Breadboard Facility. Soc. Automotive Eng. (SAE) Tech. Paper 911427.

Tani, A., A. Yamanami, Y. Kitaya, M. Kiyota, and I. Aiga. 1993. Changes in carbon dioxide and ethylene concentrations in the closed ecological chamber in which lettuce and shiitake mushroom are cultivated. CELSS J. 5(2):11-16

Wheeler, R.M., R.G. White, and F.B. Salisbury. 1986. Gravitropism in higher plant shoots. IV. Further studies on participation of ethylene. Plant Physiol. 82:534-542.

Wheeler, R.M. and T.W. Tibbitts. 1986. Growth and tuberization of potato (Solanum tuberosum L.) under continuous light. Plant Physiol. 80:801-804.

Wheeler, R.M. 1992. Gas-exchange measurements using a large, closed plant growth chamber. HortScience 27:777-780.

Wheeler, R.M., K.A. Corey, J.C. Sager, and W.M. Knott. 1993. Gas exchange rates of wheat stands grown in a sealed chamber. Crop Sci. 33:161-168.

Wheeler, R.M., B.V. Peterson, J.C. Sager, and W.M. Knott. 1996. Ethylene production by plants in a closed environment. Adv. Space Res. 18(4/5):193-196.

Wheeler, R.M., G.W. Stutte, G.V. Subbarao, and N.C. Yorio. 2001. Plant growth and human life support for space travel, p. 925-941. In: M. Pessarakli (ed.). Hndbk. Plant Crop Physiol. $2^{\text {nd }}$ ed.

Woodrow, L. and B. Grodzinski. 1989. An evaluation of the effects of ethylene on carbon assimilation in Lycopersicon esculentum Mill. J. Expt. Bot. 40:361-368. 